\title{
microRNA-16 expression in HeLa cells is upregulated in cell-cycle and drug dependent manner
}

\author{
LI Jie ${ }^{1} \&$ WU JiaRui ${ }^{1,2 *}$ \\ ${ }^{1}$ Hefei National Laboratory for Physical Sciences at Microscale and School of Life Sciences, University of Science \& Technology of China, Hefei \\ 230027, China; \\ ${ }^{2}$ Key Laboratory of Systems Biology, Institute of Biochemistry and Cell Biology, Shanghai Institutes for Biological Sciences, Chinese Academy of \\ Sciences, Shanghai 200031, China
}

Received September 8, 2010; accepted October 22, 2010

\begin{abstract}
microRNAs are single-stranded, non-coding RNAs that regulate gene expression. The microRNA-16 family has been reported to be involved in cell-cycle regulation, which could also downregulate expression of multiple pro-proliferation genes. The present results demonstrated that miR-16 expression in HeLa cells increased when the cells were arrested during S-phase under methyl methanesulfate (MMS) treatment. This further resulted in downregulation of a target protein CDC25A, whereas miR-16 expression did not increase when HeLa cells were arrested during the MMS-treated $\mathrm{G}_{0} / \mathrm{G}_{1}$ or $\mathrm{G}_{2} / \mathrm{M}$ phase. Furthermore, when HeLa cells were arrested during S-phase with hydroxyurea treatment, $m i R-16$ expression did not increase. These results suggest that expression levels of microRNAs in mammalian cells are delicately regulated under variable cellular conditions.
\end{abstract}

microRNA, cell cycle, DNA damage, methyl methanesulfate, HeLa cells

Citation: $\quad$ Li J, Wu J R. microRNA-16 expression in HeLa cells is upregulated in cell-cycle and drug dependent manner. Chinese Sci Bull, 2011, 56: 34-38, doi: $10.1007 / \mathrm{s} 11434-010-4251-8$

microRNAs (miRNAs) are single-stranded, non-coding RNAs, 21 to 23-nucleotides in length, which are generated from larger precursors transcribed from non-coding genes [1]. Results show that miRNAs, as gene regulatory molecules, are involved in many physiological and pathological processes, such as proliferation, differentiation, and tumorigenesis [2]. In addition, the function of miRNAs in mammalian cells has been shown to predominantly decrease target mRNA levels [3]. Furthermore, miRNAs could have a tuning role in regulating gene expression; and the unique features of miRNA-mediated gene regulation have recently been characterized, including the rapid turning off of protein production, as well as reversibly and compartmentalized regulating gene expression [4]. These properties could allow miRNAs to rapidly respond to subtle environmental changes or intracellular stresses.

The miRNA-16 (miR-16) family is involved in cell-cycle

*Corresponding author (email: wujr@ sibs.ac.cn) regulation, which down-regulates expression of multiple proproliferation factors, such as CDK6 and Cyclin D1, resulting in $\mathrm{G}_{0} / \mathrm{G}_{1}$ arrest $[5,6]$. Interestingly, cell-cycle inhibition of $m i R-16$ is cell-type dependent, and over-expression of miR-16 significantly increases $\mathrm{G}_{0} / \mathrm{G}_{1}$ population in HCT116, A549, and MCF7 cells, but does not induce a measurable cell-cycle change in HeLa cells [5]. In addition, repression of Cyclin D1 by miR-16 results in $\mathrm{G}_{0} / \mathrm{G}_{1}$ arrest of A549 cells, whereas the same effect leads to no $\mathrm{G}_{0} / \mathrm{G}_{1}$ accumulation in HepG2 or MEG-01 cells [6]. It is possible that $m i R-16$ targets act in concert, rather than individually, and differential effects are due to various cellular contexts.

The present study analyzed expressional change of $m i R-16$ levels in HeLa cells at different stages of cell cycle with different DNA-damage reagents. Results showed that miR-16 expression in HeLa cells was upregulated only when cells were arrested in S-phase under methyl methanesulfate (MMS) treatment. 


\section{Materials and methods}

\subsection{Materials}

Hydroxyurea (HU), methyl methanesulfate (MMS), RNase A and propidium iodide (PI) were purchased from SigmaAldrich. Fetal bovine serum (FBS) and DMEM medium were purchased from Invitrogen Life Technologies. HeLa cells were obtained from American Type Culture Collection. CDC25A antibody was purchased from Cell Signaling Technology; $\beta$-actin antibodies were purchased from SantaCruz; anti-mouse IgG, anti-rabbit IgG and ECL kit were purchased from Amersham.

\subsection{Cell culture and cell synchrony}

HeLa cells were cultured in Dulbecco's-modified Eagle's medium (DMEM) with $10 \%$ fetal bovine serum (FBS) and $100 \mathrm{U} / \mathrm{mL}$ penicillin/streptomycin (Gibco) at $37^{\circ} \mathrm{C}$. For synchronization experiments, exponentially growing HeLa cells were initially treated with $2 \mathrm{mmol} / \mathrm{L}$ hydroxyurea (HU) for $12 \mathrm{~h}$, were released in a HU-free medium for $10 \mathrm{~h}$, and then subjected to a second round of HU treatment for $12 \mathrm{~h}$. Ultimately, highly synchronized cells were obtained at the $\mathrm{G}_{1} / \mathrm{S}$ boundary. For drug-treatment experiments, HeLa cells from the HU double-block were released and subjected to $0.8-\mathrm{mmol} / \mathrm{L} \mathrm{MMS} \mathrm{treatment} \mathrm{at} \mathrm{the} \mathrm{indicated} \mathrm{time} \mathrm{points.}$

\subsection{Flow cytometric analysis}

HeLa cells were harvested and fixed with $70 \%$ ethanol at $4^{\circ} \mathrm{C}$. The fixed cells were resuspended in a PBS solution containing $500 \mu \mathrm{g} / \mathrm{mL}$ RNase A and incubated at $37^{\circ} \mathrm{C}$ for 1 h. Cellular DNA was stained with $30 \mu \mathrm{g} / \mathrm{mL}$ PI. Flow cytometry analysis was performed with a FACScalibur flow cytometer (BD FACScan).

\subsection{Western blot analysis}

HeLa cells were lysed in $1 \times$ SDS buffer $(50 \mathrm{mmol} / \mathrm{L}$ Tris, $2 \%$ SDS, $0.1 \%$ bromophenol blue, $10 \%$ glycerol, 100 $\mathrm{mmol} / \mathrm{L}$ DTT, $\mathrm{pH}$ 6.8) and boiled for $10 \mathrm{~min}$. Whole cell lysates were subjected to $10 \%$ SDS-PAGE gel electrophoresis, and the proteins were then transferred to PVDF membranes using a semi-dry transfer system (Bio-Rad). After blocking with $10 \%$ non-fat milk in TBS-T for $1 \mathrm{~h}$, the membrane was probed with primary monoclonal antibody specific to CDC25A (1:1000) for 90 min, or $\beta$-actin $(1: 2000)$ for $90 \mathrm{~min}$, which served as an internal control. Membranes were further incubated with anti-mouse $\mathrm{IgG}$ or anti-rabbit $\mathrm{IgG}$ and detected using an ECL kit.

\subsection{RNA extraction and qRT-PCR}

Total RNA from cultured HeLa cells was extracted using
Trizol Reagent (Invitrogen) according to manufacture protocols. Reverse transcription was performed using $200 \mathrm{ng}$ total RNA with $0.2 \mu \mathrm{L}$ MMLV Reverse Transcriptase (Takara) according to the manufacture protocol. qRT-PCR was performed as described using a real-time PCR Quantitation Kit (GenePharma). PCR reactions were conducted using an $\mathrm{ABI} 3000$ real-time $\mathrm{PCR}$ machine at $95^{\circ} \mathrm{C}$ for $3 \mathrm{~min}$, followed by 40 cycles of $95^{\circ} \mathrm{C}$ for $12 \mathrm{~s}$ and $62^{\circ} \mathrm{C}$ for $50 \mathrm{~s}$. Each sample was analyzed in triplicate, and U6 snRNA was used for normalization. The abundance of $m i R-16$ in HeLa cells, which was relative to the average expression, was calculated using $\mathrm{RQ}=2^{-\Delta \Delta C_{\mathrm{T}}}$, where $\Delta \Delta C_{\mathrm{T}}=\left(C_{\mathrm{T}}\right.$ miRNA $\left.-C_{\mathrm{T}} \mathrm{U} 6 \mathrm{RNA}\right)$ experimental $-\left(C_{\mathrm{T} \text { miRNA }}-C_{\mathrm{T} \text { U6 RNA }}\right)$ control.

\subsection{Anti-miR-16 transfection}

Equal numbers of HeLa cells $\left(3 \times 10^{4}\right)$ were seeded into 6 -well culture plates and cultured for $1 \mathrm{~d}$, followed by incubation with $2 \mathrm{mmol} / \mathrm{L} \mathrm{HU}$ for $12 \mathrm{~h}$. The HU-treated cells were then incubated with fresh medium and transiently transfected with synthesized anti-miR-16 oligonucleotides (miR-16 inhibitor) at a final concentration of 100, 200 and $400 \mathrm{nmol} / \mathrm{L}$ using Llipofectamine 2000 reagent (Invitrogen), respectively, for $6 \mathrm{~h}$. Synthesized random oligonucleotides served as the miR-16 negative control. Following transfection, the transfectants were re-cultured with fresh medium for an additional $4 \mathrm{~h}$, treated with $2 \mathrm{mmol} / \mathrm{L} \mathrm{HU}$ for $12 \mathrm{~h}$, and subjected to further analysis.

\section{Results and discussion}

\subsection{S-phase dependent $m i R$-16 upregulation in MMS- treated HeLa cells}

We recently reported that cell-cycle progression of HeLa cells could be arrested with a DNA damaging alkylating agent MMS, showing that cells at different phases exhibit different sensitivity to MMS treatment [7]. The same observation was shown in Figure 1(c): S-phase HeLa cells (3-h release from HU-double block; see Materials and methods) were fully arrested with $0.8 \mathrm{mmol} / \mathrm{L}$ MMS treatment, $\mathrm{G}_{2} / \mathrm{M}$-phase cells (7-h release) were partially delayed, and $\mathrm{G}_{1}$-phase cells (12-h release) were arrested at $\mathrm{G}_{0} / \mathrm{G}_{1}$ phase under the same MMS treatment. Interestingly, data from real-time PCR analysis revealed that MMS treatment significantly increased $m i R-16$ expression in S-phasearrested HeLa cells, whereas $m i R-16$ upregulation was not observed in $\mathrm{G}_{2} / \mathrm{M}$-phase and $\mathrm{G}_{0} / \mathrm{G}_{1}$-phase arrested HeLa cells under the same MMS treatment (Figure 1(d)). miR-16 expression in different phases of untreated HeLa cells (Figure 1(a)) was also measured and served as the control, of which expression levels at different phases did not reveal significant variation (Figure 1(b)). In summary, these results suggest that miR-16 upregulation in MMS-treated HeLa cells is S-phase-dependent. 
(a)

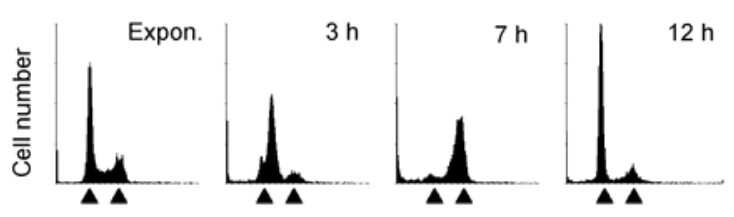

(c)
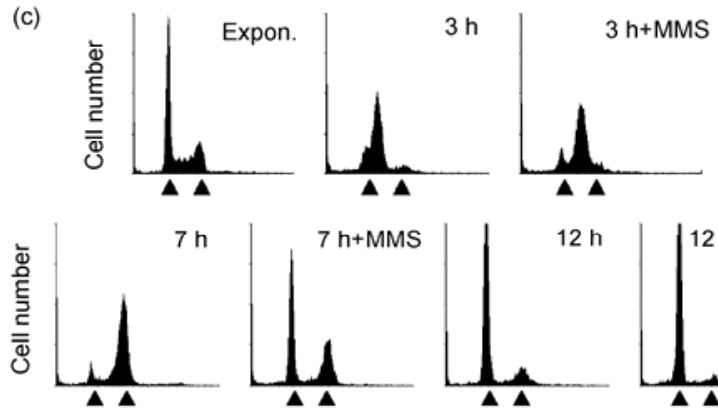

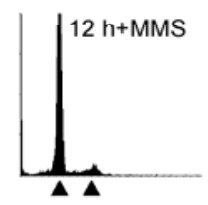

(b)

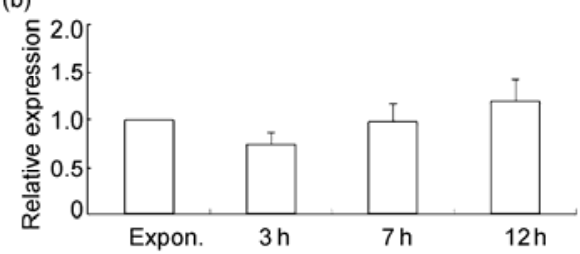

Figure 1 S-phase dependent upregulation of $m i R-16$ expression in MMS-treated HeLa cells. (a) HeLa cells were synchronized at the $\mathrm{G}_{1} / \mathrm{S}$ boundary using the HU double-block method. Synchronized HeLa cells were released from the HU-block for $3 \mathrm{~h}$ and represented S-phase cells, for $7 \mathrm{~h}$ and represented $\mathrm{G}_{2} / \mathrm{M}$-phase cells, and for $12 \mathrm{~h}$ and represented $\mathrm{G}_{1}$-phase cells. Cellular DNA contents were analyzed by flow cytometry. Arrowheads indicate $2 \mathrm{~N}$ and $4 \mathrm{~N}$ DNA contents. (b) miR-16 expression in exponentially growing HeLa cells and HeLa cells at different phases, as detected by qRT-PCR. U6 snRNA was used to normalize. Data are representative of 3 independent experiments (mean \pm SD). (c) Synchronized HeLa cells were released from HU-block for the indicated times. Subsequently, the cells were treated with $0.8 \mathrm{mmol} / \mathrm{L}$ MMS: the 3-h-released cells (S-phase cells) were treated with MMS for $4 \mathrm{~h}$, the 7-h-released cells $\left(\mathrm{G}_{2} / \mathrm{M}\right.$-phase cells) were treated with MMS for $5 \mathrm{~h}$, and the 12-h-released cells $\left(\mathrm{G}_{1}\right.$-phase cells) were treated with MMS for $6 \mathrm{~h}$. Cellular DNA contents were analyzed by flow cytometry. Arrowheads indicate $2 \mathrm{~N}$ and $4 \mathrm{~N}$ DNA contents. (d) miR-16 expression in HeLa cells at different phases, with or without MMS treatment, was detected by qRT-PCR. U6 snRNA was used to normalize. Data are representative of 3 independent experiments (mean $\pm \mathrm{SD})$. Asterisk indicates $P<0.05$.

\section{2 miR-16 upregulation results in decreased CDC25A expression}

Because CDC25A, an cell-cycle regulator in S phase [8], was reported to be negatively regulated by $m i R-16[5,9]$, expression levels of CDC25A protein in S-phase HeLa cells were measured with or without MMS treatment by Western blot analysis. Results revealed significantly downregulated CDC25A protein in S-phase-arrested HeLa cells treated with MMS (Figure 2(a) and (b)), suggesting that upregulation of $m i R-16$ expression in S-phase-arrested cells resulted in downregulated CDC25A expression. This was in agreement with a
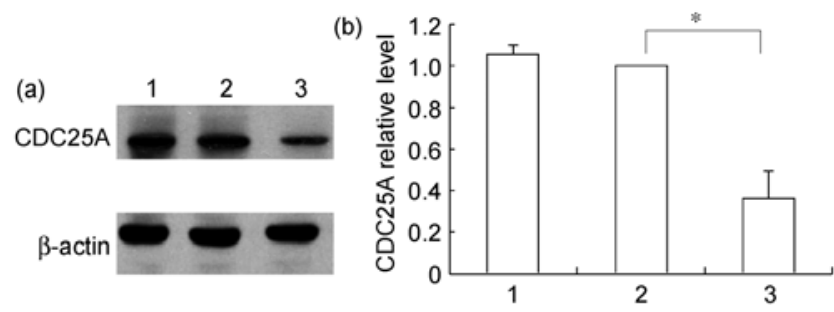

Figure 2 Up-regulation of miR-16 causes functionally decreased CDC25A proteins. (a) Western blot analysis of CDC25A in HeLa cells (lane 1, exponentially growing cells (control); lane 2, S-phase cells; lane 3, S-phase cells treated with $0.8 \mathrm{mmol} / \mathrm{L}$ MMS for $4 \mathrm{~h}$;). $\beta$-actin was used as the loading control. (b) ImageJ software was used to analyze relative CDC25A levels from the western blot results in (a). Data are representative of 3 independent experiments (mean $\pm \mathrm{SD}$ ). Asterisk indicates $P<0.05$. previous report that downregulated CDC25A transcription levels were solely dependent on UV-induced miR-16 in a $m i R-16$ knockdown experiment (see Figure 5D of ref. [9]).

The regulatory relationship between $m i R-16$ and CDC25A was further confirmed using synthesized antimiR-16 oligonucleotides (Materials and methods). Results showed that inhibition of $m i R-16$ upregulation by the $m i R-16$ inhibitor rescued the downregulation of CDC25A expression in the MMS-induced S-phase-arrested HeLa cells (Figure 3(a) and (b)). These results suggest that miR-16 directly regulate CDC25A expression, which is supported by a previous luciferase activity experiment with a RLucCDC25A-3'UTR fragment [9]. However, recovered CDC25A expression in the presence of the miR-16 inhibitor did not release the MMS-induced inhibitory effects of S-phase progression (data not shown), implying that rescue of CDC25A downregulation by $m i R-16$ alone might not be sufficient for recovery of MMS-induced S-phase-arrested HeLa cells. These results indicate that specific upregulation of $m i R-16$ expression in MMS-treated S-phase-arrested HeLa cells could functionally downregulate targets such as CDC25A.

\section{3 miR-16 expression is not upregulated in $\mathrm{HU}$-in- duced S-phase-arrested HeLa cells}

Hydroxyurea (HU) is an inhibitor of ribonucleotide reducetase 
(a)

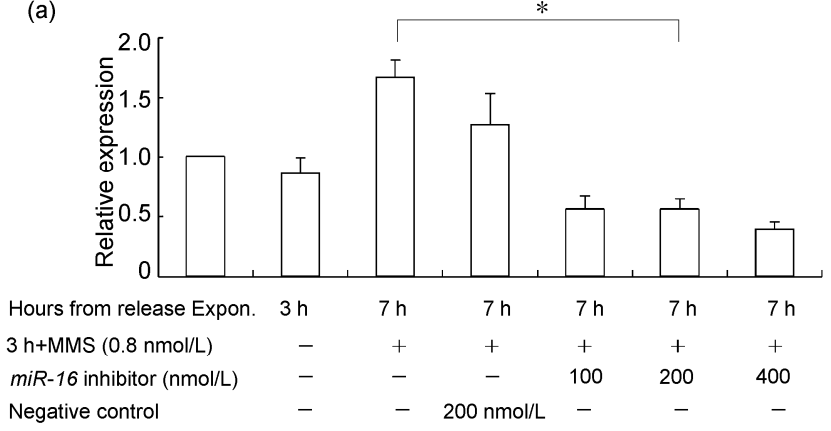

(b)

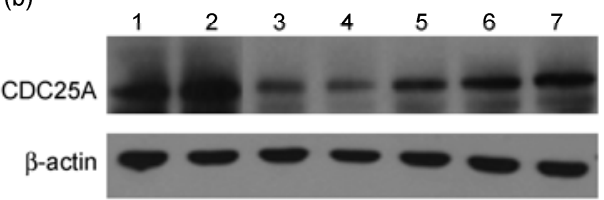

Figure 3 Inhibition of $m i R-16$ upregulation rescues downregulation of CDC25A. (a) HeLa cells were transiently transfected with $m i R-16$ inhibitor $(100,200$ and $400 \mathrm{nmol} / \mathrm{L})$ or $m i R-16$ negative control, as described in Material and methods. miR-16 expression in these cells was detected by qRT-PCR. U6 snRNA was used to normalize. Asterisk indicates $P<0.05$. (b) Western blot analysis of CDC25A in HeLa cells (lane 1, exponentially growing cells; lane 2, S-phase cells; lane 3, S-phase cells treated with MMS for $4 \mathrm{~h}$; lane 4, S-phase cells transfected with the miR-16 negative control (200 nmol/L) and treated with MMS for $4 \mathrm{~h}$; lanes 5-7, S-phase cells transfected with the miR-16 inhibitor (100, 200 and $400 \mathrm{nmol} / \mathrm{L}$, respectively) and treated with MMS for $4 \mathrm{~h}$. $\beta$-actin was used as the loading control. and has been widely used for synchronizing cells at the $G_{1} / S$ point, but it also induces DNA strand breaks in mammalian cells [10]. Our previous work showed that longer exposure to $\mathrm{HU}$ resulted in higher levels of DNA damage in $\mathrm{CHO}$ cells, as well as S-phase arrest [11]. In the present study, S-phase HeLa cells were treated with indicated concentrations of HU for $4 \mathrm{~h}$, respectively. The HU treatments resulted in arrest of HeLa cells at the S-phase (Figure 4(a)). However, real-time PCR analysis did not detect significant upregulation of miR-16 expression in HU-induced S-phasearrested cells (Figure 4(b)). Furthermore, Western blot analysis revealed similar protein levels of CDC25A between untreated S-phase HeLa cells and HU-treated S-phase cells (Figure 4(c)). In conclusion, these results showed that MMS treatment resulted in upregulation of $m i R-16$ expression, but HU treatment did not induce this effect, although both drug-treatments resulted in S-phase arrest of HeLa cells.

It is widely recognized that different kinds of DNA damage during S-phase result in differential activation of various signaling pathways in the DNA damage checkpoint [12-14]. As a widely-used DNA damaging alkylating agent, MMS adds methyl groups to DNA at 7-guanine or 3-adenine, thereby inducing structural damage or DNA single-stranded breaks [15], which often activate the base excision repair pathway [16]. In contrast, HU treatment causes DNA double-stranded breaks in mammalian cells, as well replication disturbances [10-12], which induces activation

(a)

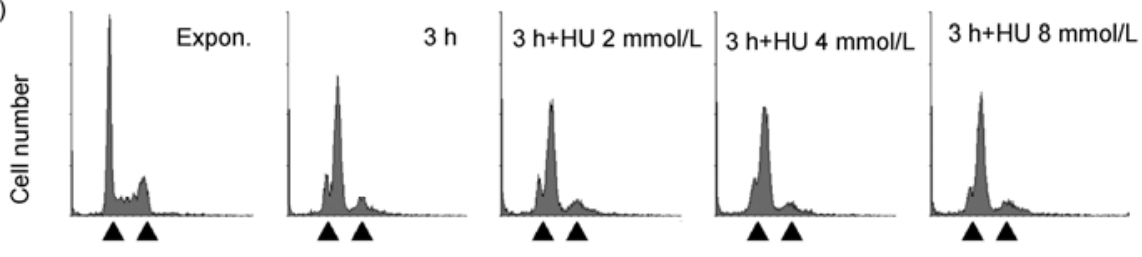

(b)
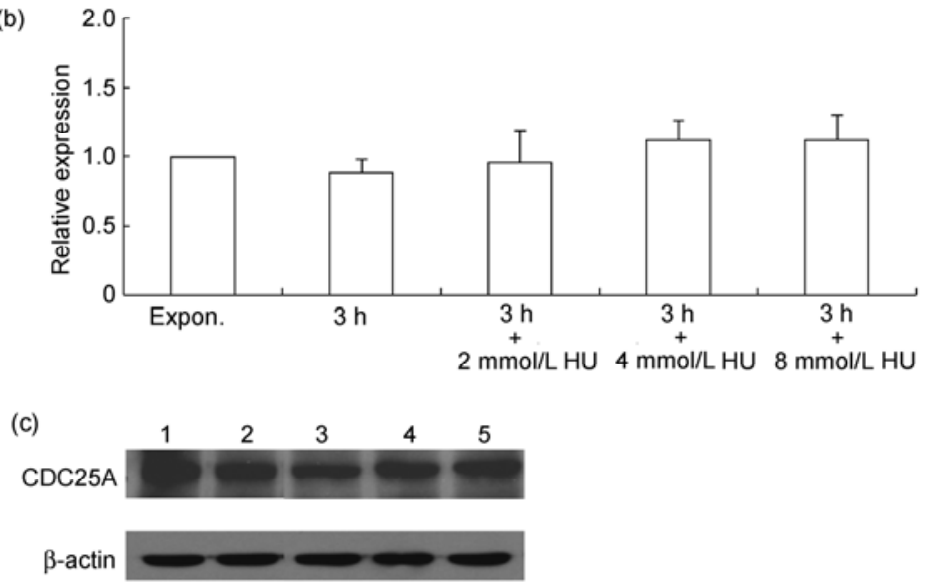

Figure 4 miR-16 expression in S-phase HeLa cells treated with HU. (a) S-phase cells were treated respectively with 2, 4 and 8 mmol/L HU for 4 h, and subjected to flow cytometry analysis. Arrowheads indicate $2 \mathrm{~N}$ and $4 \mathrm{~N}$ DNA contents. (b) S-phase cells were treated with 2 , 4 and 8 mmol/L HU for 4 h, respectively, and then miR-16 expression was detected by qRT-PCR. U6 snRNA was used to normalize. Data are representative of 3 independent experiments (mean \pm SD). (c) Western blot analysis of CDC25A of HeLa cells (lane 1, exponentially growing cells; lane 2, S-phase cells; lanes 3-5, S-phase cells treated with $\mathrm{HU}(2,4$, and $8 \mathrm{mmol} / \mathrm{L}$, respectively) for $4 \mathrm{~h}$; $\beta$-actin served as the loading control. 
of the ATM/Chk2 pathway $[17,18]$. It has been reported that MMS activates the p21-dependent S-phase DNA damage checkpoint, but suppresses the CDC25A-dependent checkpoint, whereas UV irradiation results in entirely opposite cellular responses within the same cells [19]. Based on these observations, it is possible that upregulation of $m i R-16$ expression relies on a particular cellular context determined by MMS-induced responses in terms of the S-phase checkpoint selection, whereas no such cellular context is generated under by HU treatment.

In conclusion, the present study demonstrates that expression levels of miRNAs in mammalian cells are delicately regulated under variable cellular contexts, which are determined by particular stages of the cell cycle and/or by different environmental stresses.

This work was supported by the National Key Basic Research and Development Program of China (2006CB503900), National Natural Science Foundation of China (30821065), Knowledge Innovation Program of the Chinese Academy of Sciences (KSCX1-YW-02 and KJCX2-YW-M15) and Science and Technology Commission of Shanghai Municipality (07dz05907).

1 Bartel D P. MicroRNAs: Genomics, biogenesis, mechanism, and function. Cell, 2004, 116: 281-297

2 Bartel D P. MicroRNAs: Target recognition and regulatory functions. Cell, 2009, 136: 215-233

3 Guo H, Ingolia N T, Weissman J S, et al. Mammalian microRNAs predominantly act to decrease target mRNA levels. Nature, 2010, 466: 835-840

4 Hobert O. Gene regulation by transcription factors and microRNAs. Science, 2008, 319: 1785-1786

5 Linsley P S, SchelterJ, Burchard J, et al. Transcripts targeted by the microRNA-16 family cooperatively regulate cell cycle progression. Mol Cell Biol, 2007, 27: 2240-2252

6 Liu Q, Fu H, Sun F, et al. miR-16 family induces cell cycle arrest by regulating multiple cell cycle genes. Nucleic Acids Res, 2008, 36: 5391-5404

7 Li X F, Ward T, Yao X B, et al. Chk1 prevents abnormal mitosis of S-phase HeLa cells containing DNA damage. Chinese Sci Bull, 2009, 54: 4205-4213

8 Stolfi C, Fina D, Caruso R, et al. Mesalazine negatively regulates CDC25A protein expression and promotes accumulation of colon cancer cells in S phase. Carcinogenesis, 2008, 29: 1258-1266

9 Pothof J, Verkaik N S, van IJcken W et al. microRNA-mediated gene silencing modulates the UV-induced DNA-damage response. EMBO J, 2009, 28: 2090-2099

10 Golos B, Malec J. Comparison of the effect of hydroxyurea and methotrexate on DNA fragmentation at various reaction conditions. Neoplasma, 1991, 38: 559-564

11 Jiang M R, Yang Y, Wu J R. Activation of DNA damage checkpoints in $\mathrm{CHO}$ cells requires a certain level of DNA damage. Biochem Biophys Res Commun, 2001, 287: 775-780

12 Grallert B, Boye E. The multiple facets of the intra-S checkpoint. Cell Cycle, 2008, 7: 2315-2320

13 Branzei D, Foiani M. Regulation of DNA repair throughout the cell cycle. Nat Rev Mol Cell Biol, 2008, 9: 297-308

14 Reinhardt H C, Yaffe M B. Kinases that control the cell cycle in response to DNA damage: Chk1, Chk2 and MK2. Curr Opin Cell Biol, 2009, 21: 245-255

15 Kim E M, Burke D J. DNA damage activates the SAC in an ATM/ATR-dependent manner, independently of the kinetochore. PLoS Genet, 2008, 4: e1000015

16 Horton J K, Wilson S H. Hypersensitivity phenotypes associated with genetic and synthetic inhibitor-induced base excision repair deficiency. DNA Repair (Amst), 2007, 6: 530-543

17 Ahn J Y, Schwarz J K, Piwnica-Worms H, et al. Threonine 68 phosphorylation by ataxia telangiectasia mutated is required for efficient activation of Chk2 in response to ionizing radiation. Cancer Res, 2000, 60: 5934-5936

18 Cliby W A, Roberts C J, Cimprich K A, et al. Overexpression of a kinase-inactive ATR protein causes sensitivity to DNA-damaging agents and defects in cell cycle checkpoints. EMBO J, 1998, 17: 159-169

19 Kan Q, Jinno S, Kobayashi K, et al. Cdc6 determines utilization of p21(WAF1/CIP1)-dependent damage checkpoint in S phase cells. J Biol Chem, 2008, 283: 17864-17872

Open Access This article is distributed under the terms of the Creative Commons Attribution License which permits any use, distribution, and reproduction in any medium, provided the original author(s) and source are credited. 